\title{
Rapid method of luxS and $p f s$ gene inactivation in enterotoxigenic Escherichia coli and the effect on biofilm formation
}

\author{
XIAOXU WANG ${ }^{1,2^{*}}$, SHIYU LI ${ }^{*}$, XIAORAN LU ${ }^{1}$, PAN HU $^{3}$, HAIYAN CHEN $^{4}$, \\ ZHENG LI ${ }^{1}$, ZHAOYANG BU ${ }^{1}$, XULONG LANG $^{1}$ and XINGLONG WANG ${ }^{1}$ \\ ${ }^{1}$ Key Laboratory of Jilin Province for Zoonosis Prevention and Control, \\ Institute of Military Veterinary Medicine, Academy of Military Medical Sciences, Changchun, Jilin 130122; \\ ${ }^{2}$ Institute of Special Wild Economic Animals and Plants, Chinese Academy of Agricultural Sciences, \\ Changchun, Jilin 130112; ${ }^{3}$ Key Laboratory of Zoonosis Research, Ministry of Education, \\ Institute of Zoonosis, College of Veterinary Medicine, Jilin University, Changchun, Jilin 130062; \\ ${ }^{4}$ Changchun University of Science and Technology, Changchun, Jilin 130022, P.R. China
}

Received February 2, 2015; Accepted August 24, 2015

DOI: $10.3892 / \mathrm{mmr} .2015 .4532$

\begin{abstract}
Rapid and efficient inactivation of a target gene in Escherichia coli chromosomes is required to investigate metabolic engineering. In the present study, a multiple gene inactivation approach was demonstrated in four strains of enterotoxigenic E. coli (ETEC), which are the predominant pathogenic bacteria causing piglet diarrhea, mediated by $\lambda$ Red and Xer recombination. The chromosomal genes, luxS and $p f s$ were inactivated using the multiple gene inactivation approach in the wild-type strains of E.coli, K88,K99, $987 \mathrm{P}$ and F41. This indicated that dif sites may be reused to inactivate multiple chromosomal genes when no antibiotic-resistant selectable markers remain. Following inactivation of $l u x S$ and $p f s$, the ability of ETEC to produce the quorum sensing signal, and induce auto-inducer 2 activity and biofilm formation were significantly reduced. Furthermore, the multiple gene inactivation approach also exhibits a high recombination efficiency and follows a simple process.
\end{abstract}

\section{Introduction}

Rapid and efficient inactivation of genes in microorganisms is an important process, which enables the analysis of physiological and genetic characteristics of bacteria. In recent years,

Correspondence to: Mr. Xinglong Wang, Key Laboratory of Jilin Province for Zoonosis Prevention and Control, Institute of Military Veterinary Medicine, Academy of Military Medical Sciences, 666 Liuying West Road, Changchun, Jilin 130122, P.R. China E-mail: wangxl-2006@163.com

*Contributed equally

Key words: quorum sensing, gene inactivation, biofilm formation, auto-inducer 2 chromosome gene deletion technology of Escherichia coli has developed rapidly. The method of $\lambda$ Red and FLP recombination, as described by Datsenko and Wanner (1), is a popular method to delete genes in E. coli. Baba et al (2) reported that the single gene mutation of various strains of $E$. coli was constructed using this method. The process of building multiple gene deletion strains, in order to remove the resistance genes in the mutant strains, required repeated transformation or removal of the auxiliary plasmid, which complicates the experimental process and elongates the experimental cycle. Dif sites are identified by the Xer recombinant enzyme in E. coli, which simplifies the procedure. It has been reported that one gene was successfully deleted from an E. coli chromosome using the $\lambda$ Red and Xer recombination system (3). However, whether it is suitable for multiple gene deletion in different strains and the efficiency of such deletions have not, to the best of our knowledge, been reported.

During bacterial growth specific signal molecules are secreted allowing the bacteria to monitor the population density in the surrounding environment and adjust the expression of multiple genes. This is known as quorum sensing (QS) and uses signal molecules, termed autologous inducers (AIs). In type II QS, luxS and $p f s$ genes are significant genes, involved in AI-2 synthesis (4). The pathogenic association between bacteria and host is complex and diverse; numerous studies demonstrate that the QS system of pathogenic bacteria aids in a variety of biological functions, including biofilm formation, virulence factor production, drug resistance and adhesion (5).

Biofilms are formed by bacteria adhering to surfaces and extracellular matrices (6). The biofilms of certain pathogenic bacteria are formed on the surface of tissues and organs, as well as on the surface of medical devices, which results in complications due to infection (7). According to statistical analyses, the majority of bacterial infections are caused by biofilms, which result in drug resistance, but also compromise the host immune system, markedly impacting the prevention and treatment of bacterial infection (8). Enterotoxigenic 
E. coli (ETEC) is the main cause of piglet diarrhea, a particularly serious piglet disease, and an important cause of piglet mortality. The current study focuses on enterohemorrhagic (EHEC) and enteropathogenic E. coli (EPEC). In addition, there are few studies, to the best of our knowledge, regarding ETEC, thus the present study investigates the effect of luxS and $p f s$ gene deletion on biofilm formation, in order to further elucidate the effects of virulence factor gene expression and the association with drug resistance.

\section{Materials and methods}

DNA manipulation. Pfu DNA polymerase (Agilent Technologies, Inc., Santa Clara, CA, USA) was used to generate polymerase chain reaction (PCR) products for cloning and gene insertion, and ReddyMix (Thermo Fisher Scientific, Beijing, China) was used for screening of colonies by PCR, according to standard PCR protocols. Restriction enzymes (Takara Biotechnology Co., Ltd., Changchun, China), T4 DNA ligase (Takara Biotechnology Co., Ltd.), and the PCR Purification Clean-Up kit (Takara Biotechnology Co., Ltd.) were used according to the manufacturer's instructions.

Bacterial strains and media. Four strains of ETEC served as targets in the gene integration experiments. ETEC and E. coli DH5 $\alpha$ (Takara Biotechnology Co., Ltd.) were cultured in Luria-Bertani (LB) medium (Junfeng Bioengineering Co., Ltd., Beijing, China) and antibiotic medium (Junfeng Bioengineering Co., Ltd.), in liquid broth and $1.5 \%$ agar plates containing $100 \mu \mathrm{g} / \mathrm{ml}$ ampicillin (Junfeng Bioengineering Co., Ltd.). All bacterial cultures were incubated at $37^{\circ} \mathrm{C}$, with agitation at $200 \mathrm{rpm}$ for liquid cultures. Strains and plasmids used in the present study are described in Table I.

Preparation of the homology arms with the gentamicin $(G M)$ resistance gene. The luxS and $p f s$ genes from four types of ETEC were amplified using the primers, luxS forward (F), luxS reverse (R), pfs F and pfs R. These PCR products were cloned into pMD-18T to create plasmids, p18T-luxS or p18T-pfs. The GM resistance gene was amplified from the pJN105 plasmid using primers, difGM $\mathrm{F}$ and difGM R (Table II.) This primer incorporated a 3 ' region of a gene encoding GM resistance and a $5^{\prime}$ tail that included a 28-bp E. coli dif site (dif E. coli: GGTGCGCATAATGTATATTATGTTAAAT). The plasmids, p18T-luxS and p18T-pfs were digested using EcoRV restriction enzyme, and the GM resistance gene with dif sites was cloned into the plasmids forming p18T-luxS-difGM or p18T-pfs-difGM plasmids.

The p18T-luxS-difGM and p18T-pfs-difGM plasmids were digested with both $E c o$ RI and PstI restriction enzymes, and the DNA fragments were recovered and amplified using the luxS F, luxS, Pfs F and Pfs R primers to transform the E. coli.

Preparation of competent cells and plasmid transformation. The plasmid, pKD46 was transformed into ETEC, as described by De Mey et al (9). The four strains of ETEC, with the pKD46 plasmid, were cultured in $\mathrm{LB}$ medium at $30^{\circ} \mathrm{C}$ and oscillated at $180 \mathrm{rpm}$ for $12 \mathrm{~h}$. Bacteria $(0.1 \mathrm{ml})$ was added to $1 \mathrm{ml} \mathrm{LB}$ medium containing $1 \mu \mathrm{g} / \mathrm{ml}$ ampicillin and $2 \mathrm{mmol} / \mathrm{l}$
L-arabinose (Spectrum Technology Co., Ltd., Shanghai, China), and cultured at $30^{\circ} \mathrm{C}$, with oscillation at $180 \mathrm{rpm}$. Bacteria were grown until reaching an optical density $\left(\mathrm{OD}_{600}\right)$ value of $\sim 0.6$. The culture was then placed in ice-cold water for $20 \mathrm{~min}$, and the bacteria were centrifuged at $6,000 \mathrm{x} \mathrm{g}$ for $10 \mathrm{~min}$, washed once with ice-cold water and washed twice with ice-cold 10\% glycerol (Shanghai Seagull Trading Co., Ltd., Shanghai, China) prior to collection for electroporation.

Bacterial transformation and ETEC chromosomal gene integration. The luxS or pfs gene DNA fragment (on plasmids, including the GM resistance gene and dif sites) were mixed with competent cells and placed in an electroporation cuvette (Takara Biotechnology Co., Ltd.). An electrical pulse was applied to the competent cells at $1,800 \mathrm{~V}$ for $5 \mu \mathrm{sec}$ and were then placed in LB broth containing $1 \mathrm{mmol} / \mathrm{l} \mathrm{L}$-arabinose. The cells were cultured at $30^{\circ} \mathrm{C}$, oscillated at $180 \mathrm{rpm}$ for $1 \mathrm{~h}$ and plated on GM-selective agar (Thermo Fisher Scientific, Beijing, China). The bacteria was inoculated in LB medium with GM, cultured at $30^{\circ} \mathrm{C}$ and oscillated at $180 \mathrm{rpm}$ for $24 \mathrm{~h}$. This procedure was repeated twice following which the cells were appropriately diluted with LB culture without GM and plated on a solid LB agar to exclude the strains that were unable to grow on the agar with GM. These bacteria were further identified by PCR.

Crystal violet (CV) method for quantification of biofilm formation. Biofilm assays on 6-well plates were performed, as described by Hossain and Tsuyumu (10) with certain modifications. For quantitative analysis of biofilm production, an overnight culture was grown in biofilm-inducing medium (Junfeng Bioengineering Co., Ltd.) to an $\mathrm{OD}_{600}$ of $\sim 2.0$ and diluted at 1:20. Culture medium was added to each plate and incubated for $24 \mathrm{~h}$ at $30^{\circ} \mathrm{C}$ without agitation. To remove the loosely associated bacteria, the culture was removed from the wells and rinsed three times with sterile distilled water. CV (2\%; Beijing Noble Laser Technology Co., Ltd., Beijing, China) solution was added to each well to stain the bacteria and the culture was incubated at room temperature for $15 \mathrm{~min}$. The wells were rinsed with Milli-Q water (Shanghai Seagull Trading Co., Ltd.) and 95\% ethanol was added to each CV-stained well. Absorbance $(600 \mathrm{~nm})$ was measured using a QFLC-7001 spectrophotometer (HKY Technology Co.,Ltd, Beijing, China). Six-well plates were used per experiment, and the entire experiment was performed in triplicate.

AI-2 activity assay. The AI-2 activity in cell-free E. coli culture fluids was measured using the Vibrio harveyi BB170 bioluminescence reporter assay, at $6,000 \mathrm{xg}$ for $10 \mathrm{~min}(11,12)$. Cell-free culture fluids were prepared by filtration of liquid cultures $(13,14)$ or by centrifugation, as described above. AI-2 activity was evaluated as light production compared to background light obtained with the appropriate $E$. coli growth medium. Liquid supernatant of $V$. harveyi BB120 served as the control group and E. coli $\mathrm{DH} 5 \alpha$ served as the negative control.

Statistical analysis. Results were expressed as means \pm standard deviation and analyzed using SPSS 16.0 software (SPSS, Inc., Chicago, IL, USA). Group differences were compared 
Table I. Bacterial strains and plasmids used in the current study.

\begin{tabular}{|c|c|c|c|}
\hline Strain or plasmid & Description & Serial number & Source \\
\hline \multicolumn{4}{|l|}{ Strain } \\
\hline E. coli $\mathrm{K} 88$ & Type F4 adhesin & CVCC1525 & CVMMC \\
\hline E. coli $\mathrm{K} 99$ & Type F5 adhesin & CVCC232 & CVMMC \\
\hline E. coli $987 \mathrm{P}$ & Type F6 adhesin & CVCC209 & CVMMC \\
\hline E. coli $\mathrm{F} 41$ & Type F41 adhesin & CVCC231 & CVMMC \\
\hline V. harveyi BB 120 & AI-2 detection & BAA-1116 & ATCC \\
\hline V. harveyi BB170 & AI-2 detection & BAA-1117 & ATCC \\
\hline E. coli $\mathrm{DH} 5 \alpha$ & Host of clone plasmid & & Takara Biotechnology, Co., Ltd. \\
\hline \multicolumn{4}{|l|}{ Plasmid } \\
\hline pMD18-T & $\begin{array}{l}\text { Vector for cloning polymerase chain } \\
\text { reaction products }\end{array}$ & & Takara Biotechnology, Co., Ltd. \\
\hline pJN105 & Cloning gentamicin resistance gene & & Invitrogen Life Technologies \\
\hline pKD46 & Promote E. coli chromosomal gene integration & & Invitrogen Life Technologies \\
\hline
\end{tabular}

E. coli, Escherichia coli; V. harveyi, Vibrio harveyi; AI-2, auto-inducer 2; CVMMC, Chinese veterinary microorganisms management center; ATCC, American Type Culture Collection.

Table II. PCR primers used in the current study.

\begin{tabular}{|c|c|c|c|}
\hline Name & Size (nt) & Sequence $\left(5^{\prime}\right.$ to $\left.3^{\prime}\right)$ & Function of PCR product \\
\hline \multicolumn{4}{|l|}{$\operatorname{lux} S$} \\
\hline $\mathrm{F}$ & 22 & ATGCCGTTGTTAGATAGCTTCA & \multirow[b]{2}{*}{ luxS gene amplification } \\
\hline $\mathrm{R}$ & 22 & GATGTGCAGTTCCTGCAACTTC & \\
\hline \multicolumn{4}{|l|}{ Pfs } \\
\hline $\mathrm{F}$ & 22 & TGGTAAACTATGCCTTCAAATC & \multirow[b]{2}{*}{$p f s$ gene amplification } \\
\hline $\mathrm{R}$ & 19 & GTACGACAACAAACGGGAC & \\
\hline \multicolumn{4}{|l|}{ GM } \\
\hline $\mathrm{F}$ & 28 & GGTGCGCATAATGTATATTATGTTAAAT & \multirow{2}{*}{$\begin{array}{l}\text { Gentamicin resistance and } \\
\text { gene amplification }\end{array}$} \\
\hline $\mathrm{R}$ & 27 & ATTTAACATAATATACATTATGCGCACC & \\
\hline \multicolumn{4}{|l|}{ difGM } \\
\hline $\mathrm{F}$ & 56 & ACTTCCTAGAATATATATTATGTAAACT & \multirow{4}{*}{$\begin{array}{l}\text { Gentamicin resistance gene } \\
\text { and mplification with dif } \\
\text { site }\end{array}$} \\
\hline & & GGTGCGCATAATGTATATTATGTTAAAT & \\
\hline $\mathrm{R}$ & 55 & AGTTTACATAATATATATTCTAGGAAGT & \\
\hline & & ATTTAACATAATATACATTATGCGCACC & \\
\hline
\end{tabular}

PCR, polymerase chain reaction; GM, gentamicin; F, forward; R, reverse.

using Student's t-test and $\mathrm{P}<0.05$ was considered to indicate a statistically significant difference.

\section{Results}

Gene integration and selectable marker excision. A schematic of the gene integration approach in $E$. coli using $\lambda$ Red and Xer recombination is presented in Fig. 1. The target gene from the ETEC bacteria was amplified and cloned into the pMD18-T vector. Appropriate restriction sites in the target gene were selected; however, when there was no suitable restriction site, reverse PCR amplification was used to obtain two homologous arm vectors. Fragments of the antibiotic resistance genes with dif sites at the two terminals were inserted into the target gene (in the present study, a GM resistance gene was used). The fragment, including the selectable gene, dif sites and homologous arms, was obtained from the vector by PCR amplification or restriction enzyme digestion. The fragment and pKD46 vector were subsequently transformed into ETEC. The target gene was excised as the mutated ETEC recombines with the dif site to excise the selectable gene using Xer recombination.

Construction of recombinant vector. The mutation method for the $l u x S$ and $p f s$ genes was the same, therefore, the method for $\operatorname{luxS}$ gene inactivation is presented. The $\operatorname{luxS}$ gene was amplified with primers luxS F and luxS R, and cloned into the 


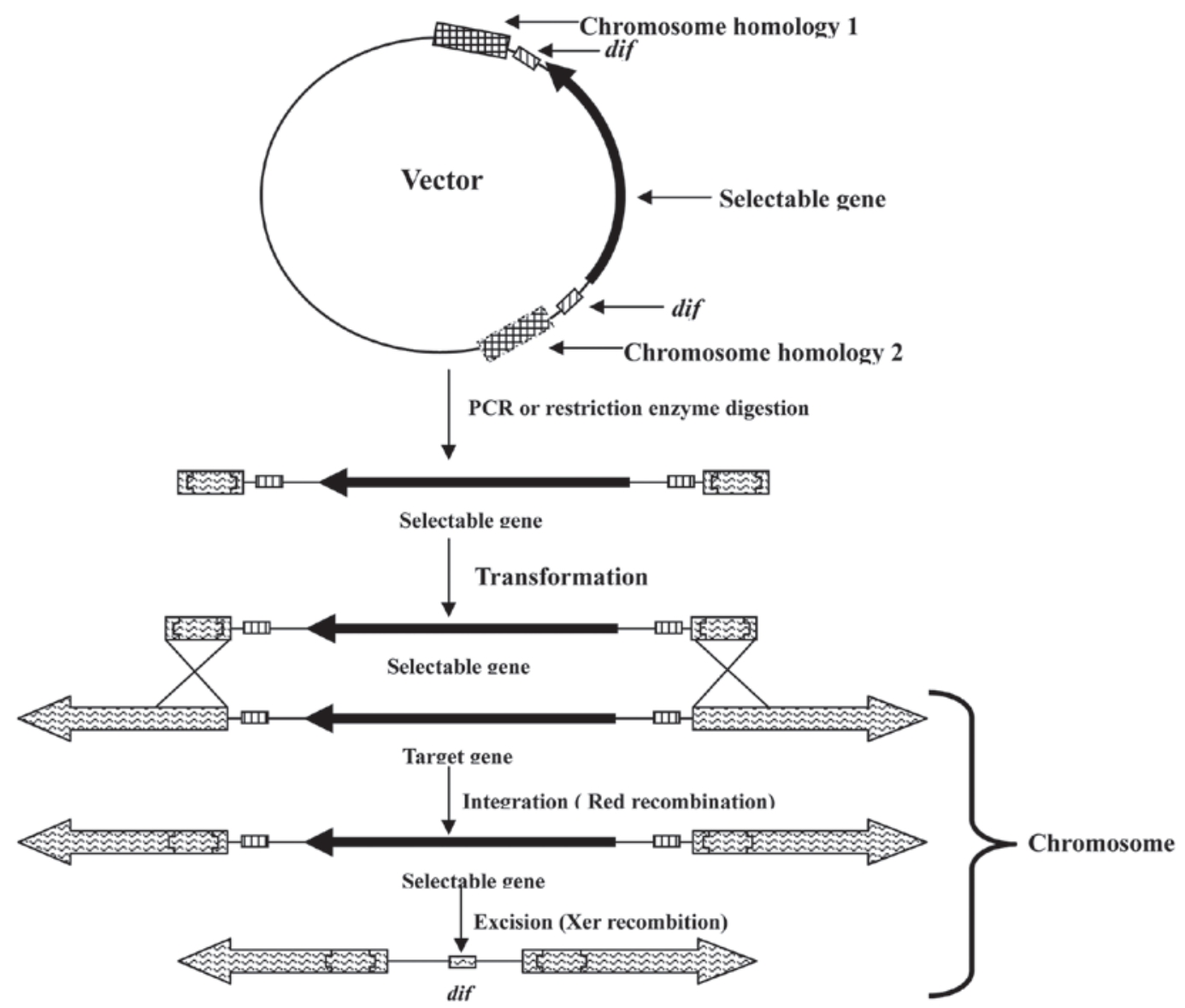

Figure 1. Chromosomal gene inactivation approach in Escherichia coli.

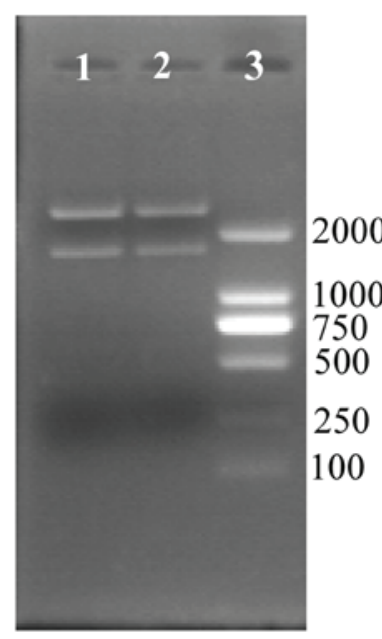

Figure 2. Agarose gel of the vector p18T-luxS-difGM was digested by EcoRI and HindIII enzyme. Lane 1 and 2, digestion product of pMD-luxS-difGm; lane 3, DNA marker of 2,000 bp.

vector, pMD18-T. The vector, pMD-luxS, was then digested by the restriction enzyme, EcoRV, and the fragment of GM resistance gene with dif sites at the two terminals was cloned into the vector. EcoRI and HindIII restriction enzymes were used to digest the vector of pMD-luxS-difGM in order to obtain the fragment from homologous recombination (Fig. 2). Two products are produced following digestion; the vector, pMD18-T and the fragment of homologous recombination.

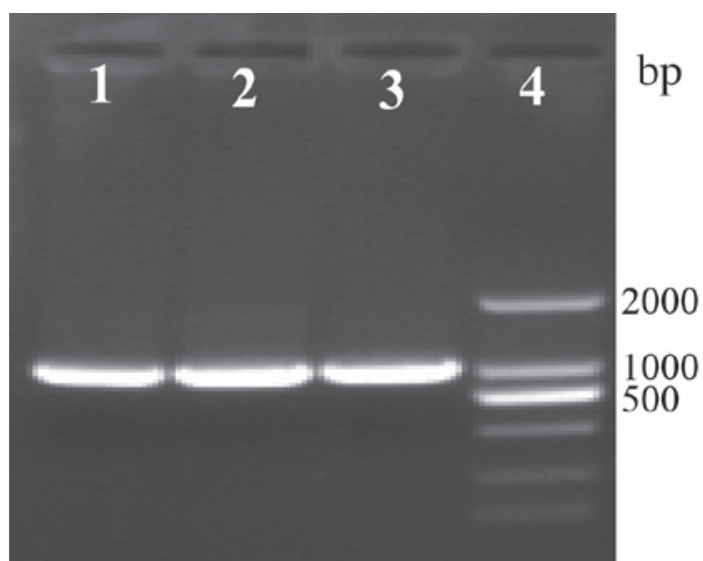

Figure 3. Agarose gel of polymerase chain reaction products generated using the forward and reverse gentamicin primers. Lane $1-3$, randomly selected bacteria (first subculture); lane 4, DNA marker of 2,000 bp.

Recombination of four strains of ETEC. Four strains of ETEC produced the same results, thus, the data presented is of $E$. coli $\mathrm{K} 88$. Three randomly selected bacteria were inoculated in LB medium with GM, amplified by GM F and GM R to produce a 1,000-bp product (Fig. 3). Amplification by luxS F and luxS R produces two products at $\sim 1,500$ and 500 bp (Fig. 4). Bacteria were then subcultured a third time, and amplified by luxS F and luxS R producing one product at $\sim 500$ bp (Fig. 5). Sequencing of the products indicated a 28-bp 


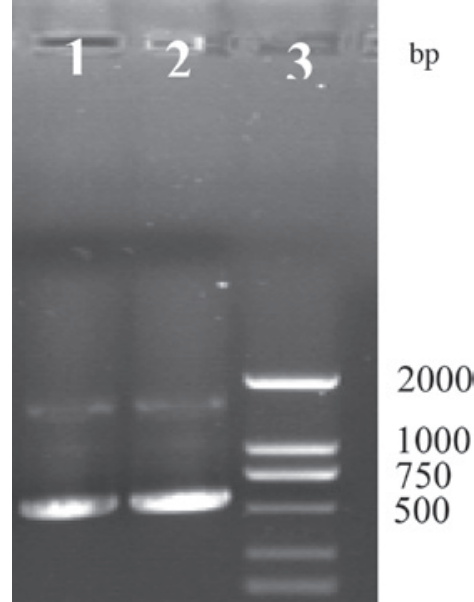

Figure 4. Agarose gel of polymerase chain reaction products generated using forward and reverse luxS primers. In the first subculture in culture medium without antibiotics, only certain strains underwent $\lambda$ Red combination, but a few bacteria underwent Xer combination. In the third subculture, all strains underwent $\lambda$ Red and Xer combination. Thus, two bands can be observed between 1,000 and 2,000 bp. Lane 1 and 2, randomly selected bacteria from the first subculture; lane 3, DNA marker of 2,000 bp.

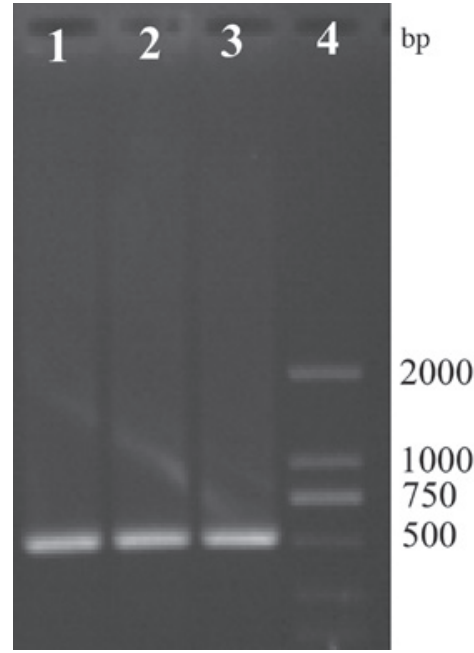

Figure 5. Agarose gel of polymerase chain reaction products generated using forward and reverse luxS primers. In the third subculture in culture medium without antibiotics, all bacteria underwent Xer combination. Thus, the band between 1,000 and 2,000 bp was missing. Lane 1-3, randomly selected bacteria from the third subculture; lane 4, DNA marker of 2,000 bp.

fragment was successfully inserted into the luxS gene (Fig. 6). These findings indicate that inactivation of the $\operatorname{luxS}$ and $p f s$ genes had been successful.

Effect of mutant strains on biofilm formation. The ability to form biofilms was observed in four strains of ETEC and is presented in Fig. 7. The ability to form biofilms was detected by crystal violet staining in both the deletion plates and the wild-type. It was demonstrated that the absorbance of the deletion plates were significantly lower compared with the wild-type, suggesting that deletion of the luxS gene resulted in a decreased ability to form biofilms. Results of ultraviolet spectrophotometry indicating absorption are presented in Table III.
Table III. Absorbance of four strains of ETEC bacteria.

\begin{tabular}{lllll}
\hline & \multicolumn{4}{c}{ Absorbance $1 /(\mathrm{g} \cdot \mathrm{cm})$} \\
\cline { 2 - 5 } Bacteria & $\mathrm{K} 88$ & $\mathrm{~K} 99$ & $987 \mathrm{P}$ & $\mathrm{F} 41$ \\
\hline Deletion & $0.21 \pm 0.04$ & $0.44 \pm 0.11$ & $0.16 \pm 0.09$ & $0.22 \pm 0.08$ \\
Wild-type & $1.17 \pm 0.11^{\mathrm{a}}$ & $1.21 \pm 0.13^{\mathrm{a}}$ & $1.57 \pm 0.19^{\mathrm{a}}$ & $1.39 \pm 0.21^{\mathrm{a}}$
\end{tabular}

Absorbance measured to determine ability to form biofilms in ETEC bacteria following deletion of $\operatorname{luxS}$ and $p f s$ genes, analyzed for significant differences between deletion and wild-type bacteria. ${ }^{\mathrm{a}} \mathrm{P}<0.01$. ETEC, enterotoxigenic Escherichia coli.

AI-2 activity detection. V. harveyi $\mathrm{BB} 170$ was used to assay the AI-2 level of ETEC. Liquid supernatant of $V$. harveyi BB120 served as the control group, E. coli DH5 $\alpha$ served as the negative control (Fig. 8). AI-2 secretion was significantly decreased following deletion of the luxS gene.

\section{Discussion}

The present study demonstrated a simple and rapid technique for selectable marker gene deletion following gene integration in bacteria, which should be applicable to all prokaryotes with the ubiquitous Xer recombination system (15). The fragment, including a selectable gene, dif sites and the chromosomal target gene was amplified by PCR, or cloned into a plasmid, and then integrated into the chromosome. ETECs that have undergone Xer recombination at dif sites during continuous culture (and have, therefore, lost the resistance gene) are identified by antibiotic sensitivity testing and verified by PCR.

Competent cells of $E$. coli demonstrate a sharp peak of transformation efficiency at an $\mathrm{OD}_{600}$ value of $\sim 0.4$ when the electroporation method is applied (16); Datsenko and Wanner (1) reported that the value was $\sim 0.6$, however the present study indicated that a value of $\sim 0.8-1.0$ obtains greater transformation efficiency. This value varies in previous studies, therefore, it is hypothesized that peak transformation efficiency varies with the strains and should be determined prior to experimentation (17). Datsenko and Wanner (1) used homologous arm fragments (length, $50 \mathrm{bp}$ ) to conduct recombination, however, the current study observed that the efficiency of homologous recombination using a fragment of $\sim 200$ bp was ten times greater than using a 50-bp fragment. In the current study, the luxS or pfs genes of ETEC were replaced with a GM resistance gene by homologous recombination. As the chromosome mutation is irreversible, the exogenous gene is highly stable in the bacteria. Throughout the present study, the efficiency of recombination was observed to be reduced when using fresh competent cells, however the efficiency was increased when the competent cells were placed in the refrigerator at $-80^{\circ} \mathrm{C}$ for $24 \mathrm{~h}$ or longer. This was observed in the four strains of ETEC that were investigated, whether the deleted gene was luxS, pfs, or ack (data not shown). The reason for this has not been determined in the current study, however, is an important factor in recombination efficiency. The Xer recombination system deletes selected genes with a homologous arm fragment by recognizing the dif site of 


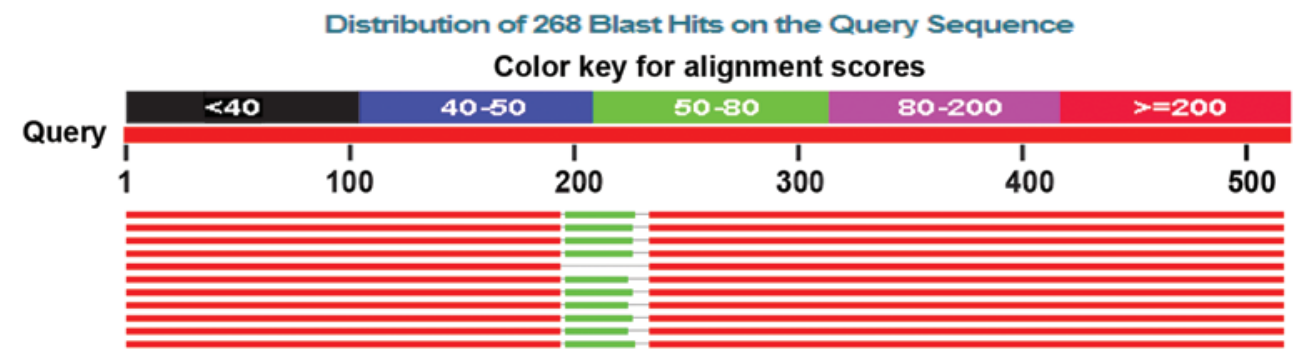

Figure 6. Sequencing results of the $\operatorname{luxS}$ gene following recombination.
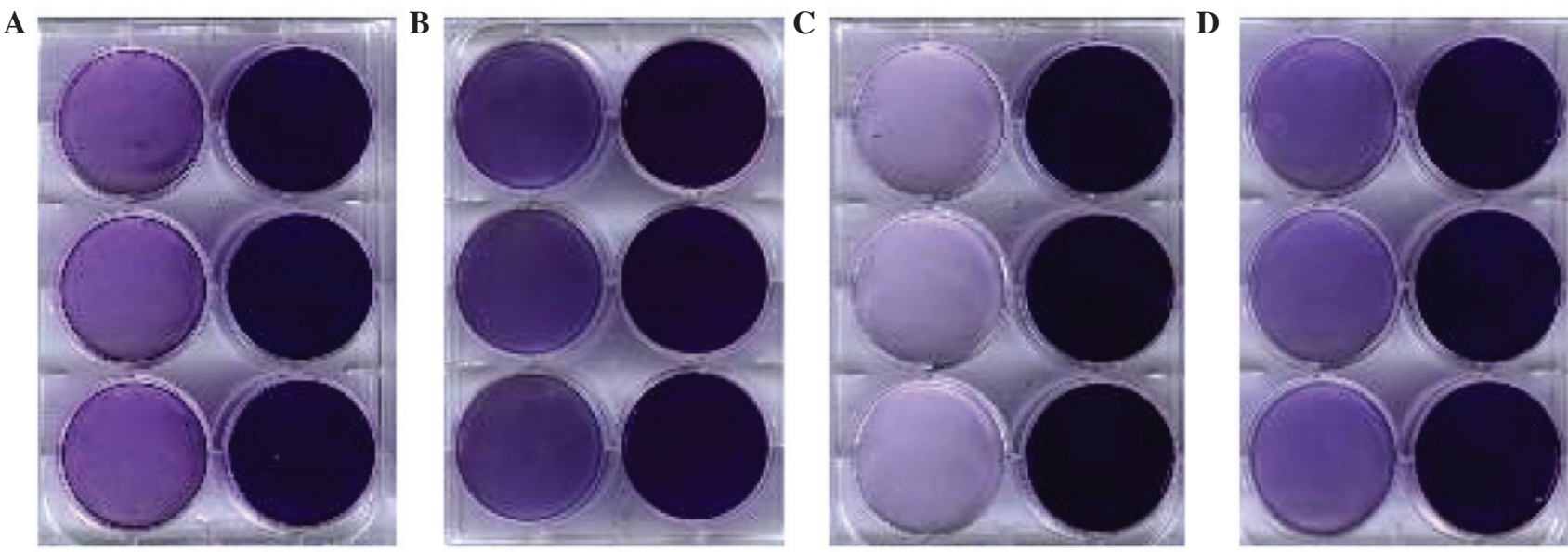

Figure 7. Effect of luxS gene was deleted upon biofilm formation. The absorbance of plates was significantly lower compared with the right side plates which shows that ability of deletion strain to form biofilms was significantly reduced. Four types of enterotoxigenic Escherichia coli are presented: (A) K88, (B) K99, (C) 987P and (D) F41. Left, luxS gene deletion strains; right, wild-type strains.

E. coli after the homologous arm has been exchanged with the chromosome. In the process of multiple gene deletion, the plasmid (such as pKD46) used in $\lambda$ Red recombination was maintained within the strain and used to delete another gene, further simplifying the experimental procedure. A previous study demonstrated that dif site recombination is not affected by antibiotic use (3). The GM resistance gene can be removed by Xer recombination, and upon addition of GM to the culture medium, a 28-bp fragment remains in the $\operatorname{luxS}$ or $p f s$ gene. The recombination efficiency of the Xer system is high. Fig. 4 presents results from the first subculture, demonstrating production of two products at $\sim 1,500$ and $500 \mathrm{bp}$. The product at $\sim 1,500 \mathrm{bp}$ was the bacterial chromosome fragment resulting from $\lambda$ Red recombination, while the $\sim 500$-bp fragment had undergone Xer recombination. The bright bands at $\sim 500$ bp suggests that the majority of bacteria used the Xer system. Fig. 5 demonstrates the third subculture, the presence of only the 500 bp product suggests all bacteria had undergone $\lambda$ Red and Xer recombination. Previous research has speculated that multiple dif sites on a chromosome may recombine again in the process of culture, leading to unstable characteristics of gene mutant strains (18). In the current study, two dif sites were used to mutate the luxS and $p f s$ genes, therefore the chromosome of the strains exhibited two dif sites, however the sites did not recombine in subsequent culture. The findings of the present study may enhance the methods of gene mutation of ETEC. More than ten ETEC genes were deleted in the present study

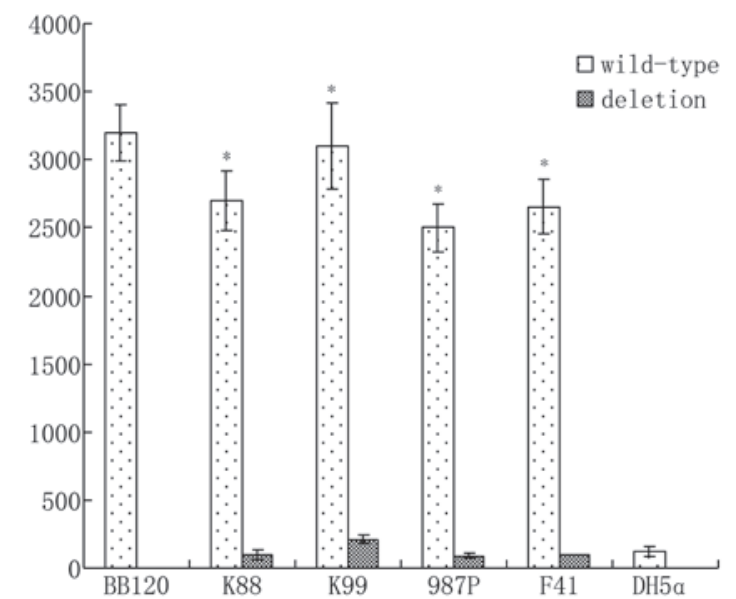

Figure 8. Auto-inducer 2 assays for deletion and wild-type of the luxS gene in enterotoxigenic Escherichia coli. ${ }^{*} \mathrm{P}<0.01$. Error bars represent mean \pm standard error of the mean.

and these strains lost the corresponding characteristic during fermentation. For example, K88 and K99 have a hemolysin toxin encoded by hlyA. The ability to destroy red blood cells was significantly decreased after deletion of the hlyA gene. The fliC gene was deleted which encoded the major flagellin protein and thus, biofilm formation was reduced in the fliC gene mutant strain. Finally, the EtpA gene was deleted, which encoded the adhesin protein. This resulted in a reduction in biofilm formation. 
QS is a cell-to-cell signaling process in bacteria enabling control of gene expression and synchronizing activities that are beneficial only at a high population density (19). QS functions via the production, secretion and detection of small molecules termed AIs; however production and detection of the majority of AIs is restricted to a single species. AI-2 (expressed by the luxS gene) is an exception as it is widely distributed in different strains of bacteria and controls distinct traits $(5,20,21)$. As a result of these characteristics, it is proposed that AI-2 is used during interspecies communication. AI-2 was discovered in $V$. harveyi and previous studies have demonstrated that certain organisms use AI-2 in the regulation of genes, which determine various functions, including expression of virulence factors in Actinobacillus actinomycetemcomitans (22,23), EHEC O157:H7 (24), P. gingivalis $(25,26)$, Streptococcus pyogenes (27), Vibrio cholerae (28-30), and Vibrio vulnificus (31); motility in Campylobacter jejuni (32), EHEC O157:H7 and EPEC E. coli O127:H6 $(33,34)$; cell division in E. coli W3110 and EHEC O157:H7 (35,36); production of antibiotics in Photorhabdus luminescens (37); biofilm formation in Streptococcus gordonii (38); and an AI-2 ATP binding cassette-type transporter in Salmonella enterica serovar Typhimurium (39). This previous research demonstrates the wide variety of bacteria using AI-2 to control a diverse range of function-specific genes.

Previous studies suggest that the expression of virulence factors and metabolism of $E$. coli bacteria were regulated by the $\operatorname{luxS}$ gene (40). Further analysis determined that luxS performs a variety of functions, regulates the expression of hundreds of genes, determines population density and regulates biofilm formation by synthesis of AI-2 signal molecules. In addition, exogenous AI-2 enhances biofilm formation and the mechanism may function via the expression of flagella, which induce bacterial activity (41-43); however, these previous studies focused on EHEC and EPEC or other strains of E. coli. In the current study, four strains of ETEC were used and it was demonstrated that the ability to form biofilms was significantly reduced without the luxS gene (Fig. 7 and Table III). The result suggests that the effect of $\operatorname{luxS}$ on biofilm formation in ETEC is widespread, with the largest impact observed on $987 \mathrm{P}$ and the smallest on K99. Current research on ETEC is minimal, therefore, the aim of the present study was to demonstrate that multiple gene inactivation to delete the luxS gene (or other genes) may be used to evaluate the influence of AI-2 on biofilm formation, the associated drug resistance and virulence factors in order to contribute to the prevention and treatment of piglet diarrhea.

In conclusion, gene inactivation by $\lambda$ Red and Xer recombination is a rapid, efficient and stable method for deletion of ETEC genes. Deletion of $l u x S$ and $p f s$ significantly reduces the activity of AI-2 and the ability of ETEC to form biofilms. However, further investigation is required to elucidate the effect of QS on the expression of virulence genes and drug resistance.

\section{Acknowledgements}

The present study was supported by the Chinese Postdoctoral Science Foundation (grant no. 2014M552581).

\section{References}

1. Datsenko KA and Wanner BL: One-step inactivation of chromosomal genes in Escherichia coli K-12 using PCR products. Proc Natl Acad Sci USA 97: 6640-6645, 2000.

2. Baba T, Ara T, Hasegawa M, Takai Y, Okumura Y, Baba M, Datsenko KA, Tomita M, Wanner BL and Mori H: Construction of Escherichia coli K-12 in-frame, single-gene knockout mutants: The Keio collection. Mol Syst Biol 2: 2006.0008, 2006.

3. Bloor AE and Cranenburgh RM: An efficient method of selectable marker gene excision by Xer recombination for gene replacement in bacterial chromosomes. Appl Environ Microbiol 72: 2520-2525, 2006.

4. Beeston AL and Surette MG: pfs-dependent regulation of autoinducer 2 production in Salmonella enterica serovar Typhimurium. J Bacteriol 184: 3450-3456, 2002.

5. Xavier KB and Bassler BL: LuxS quorum sensing: More than just a numbers game. Curr Opin Microbiol 6: 191-197, 2003.

6. Costerton JW, Stewart PS and Greenberg EP: Bacterial biofilms: A common cause of persistent infections. Science 284: 1318-1322, 1999.

7. Kozlova EV, Popov VL, Sha J, Foltz SM, Erova TE, Agar SL, Horneman AJ and Chopra AK: Mutation in the S-ribosylhomocysteinase (luxS) gene involved in quorum sensing affects biofilm formation and virulence in a clinical isolate of Aeromonas hydrophila. Microb Pathog 45: 343-354, 2008.

8. Hancock V, Dahl M and Klemm P: Probiotic Escherichia coli strain Nissle 1917 outcompetes intestinal pathogens during biofilm formation. J Med Microbiol, 59: 392-399, 2010.

9. De Mey M, De Maeseneire S, Soetaert W and Vandamme E: Minimizing acetate formation in $E$. coli fermentations. J Ind Microbiol Biotechnol 34: 689-700, 2007.

10. Hossain MM and Tsuyumu S: Flagella-mediated motility is required for biofilm formation by Erwinia carotovora subsp. carotovora. J Gen Plant Pathol 72: 34-39, 2006.

11. Bassler BL, Wright M, Showalter RE and Silverman MR: Intercellular signalling in Vibrio harveyi: Sequence and function of genes regulating expression of luminescence. Mol Microbiol 9: 773-786, 1993.

12. Bassler BL, Wright $M$ and Silverman MR: Multiple signalling systems controlling expression of luminescence in Vibrio harveyi: Sequence and function of genes encoding a second sensory pathway. Mol Microbiol 13: 273-286, 1994.

13. Surette MG and Bassler BL: Quorum sensing in Escherichia coli and Salmonella typhimurium. Proc Natl Acad Sci USA 95: 7046-7050, 1998.

14. Surette MG and Bassler BL: Regulation of autoinducer production in Salmonella typhimurium. Mol Microbiol 31: 585-595, 1999.

15. Recchia GD and Sherratt DJ: Conservation of xer site-specific recombination genes in bacteria. Mol Microbiol 34: 1146-1148, 1999.

16. Sambrook J and Russell DW: Molecular cloning: A laboratory Manual 3rd Edn. New York: Cold Spring Harbor Laboratory Press, 2001: 1.199-1.122.

17. Zhou Li, Niu Dan-Dan, Li Ning, Chen Xian-Zhong, Shi Gui-Yang and Wang Zheng-Xiang: Multiple gene inactivation approach in Escherichia coli mediated by a combination of red recombination and Xer recombination. Microbiology China 37: 923-928, 2010.

18. Zhou L, Niu DD, Li N, Chen XZ, Shi GY and Wand ZX: Multiple gene inactivation approach in Escherichia coli mediated by a combination of red recombination and Xer recombination. Microbiol China 37: 923-928, 2010.

19. Xavier KB and Bassler BL: Regulation of uptake and processing of the quorum-sensing autoinducer AI-2 in Escherichia coli. J Bacteriol 187: 238-248, 2005.

20. Federle MJ and Bassler BL: Interspecies communication in bacteria. J Clin Invest 112: 1291-1299, 2003.

21. Surette MG, Miller MB and Bassler BL: Quorum sensing in Escherichia coli, Salmonella typhimurium, and Vibrio harveyi: A new family of genes responsible for autoinducer production. Proc Natl Acad Sci USA 96: 1639-1644, 1999.

22. Fong KP, Chung WO, Lamont RJ and Demuth DR: Intra-and interspecies regulation of gene expression by Actinobacillus actinomycetemcomitans LuxS. Infect Immun 69: 7625-7634, 2001.

23. Fong KP, Gao L and Demuth DR: luxS and arcB control aerobic growth of Actinobacillus actinomycetemcomitans under iron limitation. Infect Immun 71: 298-308, 2003 
24. Sperandio V, Mellies JL, Nguyen W, Shin S and Kaper JB Quorum sensing controls expression of the type III secretion gene transcription and protein secretion in enterohemorrhagic and enteropathogenic Escherichia coli. Proc Natl Acad Sci USA 96: 15196-15201, 1999.

25. Burgess NA, Kirke DF, Williams P, Winzer K, Hardie KR, Meyers NL, Aduse-Opoku J, Curtis MA and Cámara M: LuxS-dependent quorum sensing in Porphyromonas gingivalis modulates protease and haemagglutinin activities but is not essential for virulence. Microbiology 148: 763-772, 2002.

26. Chung WO, Park Y, Lamont RJ, McNab R, Barbieri B and Demuth DR: Signaling system in Porphyromonas gingivalis based on a LuxS protein. J Bacteriol 183: 3903-3909, 2001.

27. Lyon WR, Madden JC, Levin JC, Stein JL and Caparon MG: Mutation of luxS affects growth and virulence factor expression in Streptococcus pyogenes. Mol Microbiol 42: 145-157, 2001.

28. Lenz DH, Mok KC, Lilley BN, Kulkarni RV, Wingreen NS and Bassler BL: The small RNA chaperone Hfa and multiple small RNAs control quorum sensing in Vibrio harveyi and Vibrio cholerae. Cell 118: 69-82, 2004.

29. Miller MB, Skorupski K, Lenz DH, Taylor RK and Bassler BL: Parallel quorum sensing systems converge to regulate virulence in Vibrio cholerae. Cell 110: 303-314, 2002.

30. Zhu J, Miller MB, Vance RE, Dziejman M, Bassler BL and Mekalanos JJ: Quorum-sensing regulators control virulence gene expression in Vibrio cholerae. Proc Natl Acad Sci USA 99: 3129-3134, 2002.

31. Kim SY, Lee SE, Kim YR, Kim CM, Ryu PY, Choy HE, Choy SS and Rhee JH: Regulation of Vibrio vulnificus virulence by the LuxS quorum-sensing system. Mol Microbiol 48: 1647-1664, 2003.

32. Elvers KT and Park SF: Quorum sensing in Campylobacter jejuni: Detection of a luxS encoded signalling molecule. Microbiology 148: 1475-1481, 2002.

33. Girón JA, Torres AG, Freer E and Kaper JB: The flagella of enteropathogenic Escherichia coli mediate adherence to epithelial cells. Mol Microbiol 44: 361-379, 2002.
34. Sperandio V, Torres AG and Kaper JB: Quorum sensing Escherichia coli regulators B and C (QseBC): A novel two-component regulatory system involved in the regulation of flagella and motility by quorum sensing in E. coli. Mol Microbiol 43: 809-821, 2002.

35. DeLisa MP, Wu C-F, Wang L, Valdes JJ and Bentley WE: DNA microarray-based identification of genes controlled by autoinducer 2-stimulated quorum sensing in Escherichia coli. J Bacteriol 183 . 5239-5247, 2001

36. Sperandio V, Torres AG, Girón JA and Kaper JB: Quorum sensing is a global regulatory mechanism in enterohemorrhagic Escherichia coli O157:H7. J Bacteriol 183: 5187-5197, 2001.

37. Derzelle S, Duchaud E, Kunst F, Danchin A and Bertin P: Identification, characterization, and regulation of a cluster of genes involved in carbapenem biosynthesis in Photorhabdus luminescens. Appl Environ Microbiol 68: 3780-3789, 2002.

38. McNab R, Ford SK, El-Sabaeny A, Barbieri B, Cook GS and Lamont RJ: LuxS-based signaling in Streptococcus gordonii: autoinducer 2 controls carbohydrate metabolism and biofilm formation with Porphyromonas gingivalis. J Bacteriol 185: 274-284, 2003.

39. Taga ME, Semmelhack JL and Bassler BL: The LuxS-dependent autoinducer AI-2 controls the expression of an ABC transporter that functions in AI-2 uptake in Salmonella typhimurium. Molecular Microbiology 42: 777-793, 2001.

40. Walters $M$ and Sperandio V: Quorum sensing in Escherichia coli and Salmonella. Int J Med Microbiol 296: 125-131, 2006.

41. Beloin C, Roux A and Ghigo J-M: Escherichia coli biofilms. In: Bacterial Biofilms. Romeo T (ed). Springer, Berlin Heidlberg, pp249-289, 2008.

42. Naves P, del Prado G, Huelves L, Gracia M, Ruiz V, Blanco J, Dahbi G, Blanco M, Ponte MC and Soriano F: Correlation between virulence factors and in vitro biofilm formation by Escherichia coli strains. Microb Pathog 45: 86-91, 2008.

43. Yamaguchi Y, Park JH and Inouye M: MqsR, a crucial regulator for quorum sensing and biofilm formation, is a GCU-specific mRNA interferase in Escherichia coli. J Biol Chem 284: 28746-28753, 2009. 